\title{
O TRABALHO DO CARTÓgRAFO DO PONTO DE VISTA DA ATIVIDADE
}

\author{
Maria Elizabeth Barros de Barros ${ }^{I} \star$ Fabio Hebert da Silva ${ }^{I I} \star \star$ \\ ${ }^{I}$ Universidade Federal do Espírito Santo, Vitória, ES - Brasil \\ II Universidade Federal Fluminense, Campos, RJ - Brasil
}

\begin{abstract}
Resumo
Neste artigo são apresentadas diretrizes para pensar o trabalho do pesquisador cartógrafo do ponto de vista da atividade, a partir de contribuições das Clínicas do Trabalho. $O$ desdobramento dessas diretrizes leva à proposição de um gênero pesquisador-cartógrafo. A partir de uma pesquisa com docentes em instituições de ensino superior privada na Grande Vitória, são compartilhadas algumas reflexões sobre a complexidade das relações que constituem esse gênero pesquisador-cartógrafo. Nessa pista do método cartográfico considera-se que a atividade do cartógrafo é a constituição de um gênero sempre em vias de estilização, em meio a processos de aprendizagem e intervenções reciprocas. Esse gênero sempre toma como objeto uma atividade e tem como aposta metodológica a problematização da atividade do pesquisador, que convoca para o diálogo pesquisadores engajados num modo de fazer pesquisa que considera a experiência situada com suas irregularidades e imprevistos.
\end{abstract}

Palavras-chave: metodologia de pesquisa; método da cartografia; atividade; clínicas do trabalho.

\section{THE CARTOGRAPHER'S WORK FROM THE ACTIVITY'S POINT OF VIEW}

\begin{abstract}
In this article are guidelines to think the work of the researcher cartographer, from the activity's point of view, from contributions of Clinics of Labor. The unfold of these guidelines leads to the proposition of a gender researcher cartographer. From a research with teachers in private higher education institutions in Greater Vitória, shares some thoughts about the complexity of relations that constitute this

\footnotetext{
^ Psicóloga. Possui mestrado em Psicologia Escolar pela Universidade Gama Filho, doutorado em Educação pela Universidade Federal do Rio de Janeiro e pós doutorado em saúde pública pela ENSP/Fiocruz. Atualmente é professora titular da Universidade Federal do Espírito Santo. Endereço: Universidade Federal do Espírito Santo, Centro de Ciências Humanas e Naturais, Departamento de Psicologia. Av. Fernando Ferrari, s/n - Goiabeiras. Vitoria, ES - Brasil. CEP: 29060900.

E-mail: betebarros@uol.com.br pela Universidade Federal Fluminense, doutorado em Educação pela Universidade Federal do Espírito Santo. Docente da Universidade Federal Fluminense (Campos/RJ), Psicologia. E-mail: fabiohebert@gmail.com
}

$\star \star$ Psicólogo. Possui especialização em Transdisciplinaridade e Clínica; mestrado em Psicologia
\end{abstract}


researcher cartographer gender. On this track of cartographic method is considered that the activity of the cartographer is the establishment of gender always styling amid learning processes and interventions reciprocal. This gender always takes as an object the activity and its methodological bet problematize the activity of the researcher, which calls for dialogue researchers engaged in a way of doing research that considers the experience located with its irregularities and unexpected.

Keywords: research methodology; method of cartography; activity; clinics of labor.

Neste texto apresentamos diretrizes gerais para pensar o trabalho do pesquisador cartógrafo do ponto de vista da atividade, a partir de contribuições das Clínicas do Trabalho. A primeira dessas diretrizes expressa um método de pesquisa no qual o processo de produção de conhecimento se faz como um construtivismo radical, desafiando o pensamento a superar o modelo da representação. A outra é a de que o trabalho de pesquisa, pensado do ponto de vista da atividade, se dá na relação entre o prescrito e o real, uma vez que não é a obediência irrestrita a procedimentos protocolares e técnicas formuladas previamente, que antecedem a entrada no campo empírico.

Da primeira diretriz retomamos a máxima socioanalítica segundo a qual é preciso transformar para conhecer. Conhecer implica ação e intervenção no plano do instituído. A atividade de pesquisa é ela mesma uma ação criadora de mundos e sujeitos e não serve como acesso à experiência a ser desvelada, já que o pesquisador encontra processos em curso quando inicia uma investigação, o que confere um caráter construtivista à atividade cartográfica.

Da segunda diretriz destacamos a pesquisa cartográfica como atividade humana, expressando-se, portanto, como constante reformulação e análise das aproximações a um determinado campo problemático. A partir dessas duas diretrizes, consideramos que um cartógrafo sempre se depara com uma dupla dimensão das situações concretas: um "vazio de normas" (SCHWARTZ, 1998) por um lado, e "normas antecedentes" (SCHWARTZ, 1992) por outro. As tarefas predefinidas nos projetos de pesquisa que direcionam a entrada no campo disparam um "debate de normas" (CANGUILHEM, 2000) que caracteriza toda atividade de trabalho, uma vez que os humanos não cessam de fazer escolhas. O pesquisador precisa lidar com um patrimônio constituído na história dos modos de fazer pesquisa, fazer escolhas por direções e, ao mesmo tempo, lida com a emergência do singular. Aqui se anuncia um postulado ergológico: "Toda atividade de trabalho é sempre, em algum grau, de um lado descritível como um protocolo experimental e, de outro, experiência e encontro" (SCHWARTZ, 2000, p. 485).

Temos, assim, normas encontradas, já dadas em um meio, normas antecedentes, mas, também, e, principalmente, infidelidades em função não só de diferentes variabilidades que o viver nos impõe, como também pelo acaso, pela indeterminação, pelas tarefas heterodeterminadas. O pesquisador é convocado não só a aprender as regras que regem uma determinada situação, como também a 
criar normas de funcionamento para as situações sempre singulares, enfrentando o que emerge em situação de irregularidade. Tal dinâmica exige regulações e regulagens (ATHAYDE; BRITTO, 2010). Nessa linha de argumentação, a atividade exige um debate constante de experiências e saberes diversos que lança o pesquisador a um processo perpétuo de transformação-conhecimento das atividades que desenvolvem.

Esse postulado, portanto, trata de um trabalho que não se reduz à aplicação de um procedimento: trabalhar é exercitar um pensamento e é também viver, é "irradiar" (CANGUILHEM, 2000), é se confrontar com um mundo de normas que antecipa o agir, visando imprimir-lhe marcas singulares. $\mathrm{O}$ trabalhar em pesquisa não significa, por conseguinte, compor um programa de possibilidades a ser repertoriado; é escolher, decidir em meio a um mundo de valores, é arbitrar.

Essas orientações demandam, a nosso ver, a criação de intercessores que nos ajudem a avançar na tarefa de construção de estratégias metodológicas que estejam em sintonia com o caráter processual da investigação. Seguindo Deleuze e Guattari (1997), não se persegue a construção de estratégias que fazem decalque do que se quer tratar, nem o desvelamento da essência do que se investiga, sem preocupação com o seu caráter genético. Não se trata, tampouco, de assumir uma atitude demonstrativa, mas de afirmar uma dimensão construtivista da produção de conhecimento, uma experimentação ancorada numa realidade movente, com valores e normas forjadas na história, desconfiando-se sempre da fixidez da realidade a ser pesquisada. Eis, então, as questões que vamos enfrentar: O que é a atividade de pesquisar objetos de natureza processual? Como entender a pesquisa como uma atividade que não busca verificação de hipóteses ou que se limita à resolução de problemas? (WISNER, 1999).

Essas questões, indubitavelmente, colocam-se para a atividade de pesquisa cartográfica. O cartógrafo renormatiza, opera num vazio de normas que o convoca à criação, exerce sua inventividade em meio aos desafios que o campo empírico coloca. Não sabemos de antemão o que vamos encontrar nas situações concretas de pesquisa, é preciso construir normas que deem conta desse vazio que se coloca entre as prescrições e os desafios e variabilidades do real. Mas é preciso ter algumas direções, pistas, que nos ajudem na construção dessas vias, na aventura investigativa. Não se trata de recusar toda e qualquer orientação. É preciso examinar e construir os caminhos de pesquisa no curso das intervenções.

A partir desse quadro, destacamos, nesse texto, uma dupla afirmação para os processos de trabalho em pesquisa cartográfica: a) a cartografia toma a atividade como fenômeno a ser investigado; b) a atividade do próprio cartógrafo deve ser analisada no processo de pesquisa, uma vez que a atividade de pesquisa produz o pesquisador e o campo. Os atos dos cartógrafos participam e intervém nas mudanças e "[...] nas derivas transformadoras que aí estão" (ESCÓSSIA; TEDESCO, 2009, p. 106). 


\section{Das Clínicas do trabalho COMO INTERCESSORAS do MÉtOdo CARTOGRÁFICO}

Fazer pesquisa nessa direção cartográfica é considerar que a realidade a ser pesquisada se apresenta como mapa móvel. Habitualmente, o que se nomeia como metodologia é da ordem de regras previamente estabelecidas, como nos indica a etimologia da palavra que anuncia a existência de um caminho (hodos) predeterminado para se alcançar algumas metas - "métahodos", o que indicaria a necessidade de um rigor e precisão metodológicos, entendidos como obediência mecânica a procedimentos apriorísticos (PASSOS; BENEVIDES DE BARROS, R. 2009).

A direção impressa na pesquisa cartográfica, entretanto, é outra: a precisão não é exatidão, já que não representa de forma fidedigna a realidade pesquisada por meio de passos a serem seguidos. Ela estaria próxima dos movimentos da vida, da normatividade do vivo e é tomada como compromisso e interesse, intervenção. O que se privilegia é o acompanhamento das linhas de força que compõem uma experiência, privilegiando-se não um estado de coisas, mas, principalmente, o que está em vias de ser (PASSOS; BENEVIDES DE BARROS, 2009).

É partindo dessa paisagem conceitual-política que entendemos que as Clínicas do Trabalho podem ser aliadas importantes na formulação de pistas para um método cartográfico. Sim, pistas, se entendermos que não é possível, nem aconselhável, a definição de regras rígidas a serem seguidas nos processos investigativos. As Clínicas do Trabalho indicam um processo de constituição de estratégias metodológicas que não buscam definir a totalidade dos procedimentos, controle de variáveis e regras para pesquisar atividade de trabalho.

Como um conjunto heterogêneo de abordagens teórico-metodológicas, as Clínicas do Trabalho têm como foco de análise o estudo dos modos de subjetivação em meio às situações de trabalho, com o entendimento de que trabalho é "atividade industriosa", como nos indica Schwartz (1998). Clínica não como prática voltada para problemáticas intrapsíquicas, que abordam a subjetividade como da ordem de uma interioridade descolada das condições de sua produção, isolada das situações concretas de sua emergência. Trata-se desse modo, de uma Clínica que privilegia o trabalho em situação concreta, dando relevância às conexões entre sujeitos e processos laborais. É essa direção que nos interessa para pensar o trabalho do pesquisador-cartógrafo: por um lado, tomar a pesquisa em situação, e, por outro, tomar a pesquisa como trabalho de pesquisa.

Lhuilier (2006), em seus estudos sobre as Clínicas do Trabalho, afirma que essas clínicas fazem pesquisa como intervenção privilegiando-se os processos criadores dos sujeitos em situação de trabalho, sua capacidade de mobilização, de agir e de se submeter às provas do real, uma vez que o real indaga as prescrições previamente definidas. Como sinaliza, as Clínicas do Trabalho não constituem uma escola de pensamento com homogeneidade teórica, epistemológica ou metodológica. O que se destaca é o interesse pela ação no trabalho, mais 
exatamente, pelo "poder de agir" (CLOT, 2006) dos humanos em situação de trabalho. Poder no sentido de enfrentamento dos desafios que o real porta, é maestria, manejo da própria atividade de pesquisa.

É no confronto com o real e suas resistências que se forja o corpo dos sujeitos em situação de trabalho, no nosso caso, do pesquisador em atividade de pesquisa. $\mathrm{O}$ foco está dirigido, reafirmamos, para o concreto das situações em que a pesquisa se desenvolve. $\mathrm{O}$ trabalho do pesquisador, a partir desse quadro, não pode ser expediente de coleta de dados sobre uma realidade constituída e, sim, pesquisa engajada, cujas separações entre sujeito e objeto são recusadas.

Para os propósitos desse texto, privilegiamos, entre essas Clínicas do Trabalho, a Ergologia e a Clínica da Atividade. A primeira, porque coloca a questão da transformação dos processos de trabalho como prioridade. A atividade é tomada como "matriz da história humana" (SCHWARTZ, 1992), é estudada no fluxo das ações, o que está em consonância com a direção de pesquisa proposta pela cartografia. A Ergologia propõe uma abertura máxima da atenção para as dimensões da atividade humana. Mais do que capacidade de reagir, viver diz de um movimento de desanonimar o meio, entalhando-o de forma singular. Tal desnaturalização implica riscos que toda arbitragem contempla, pois implica submeter-se à prova do real, ou seja, ao que indaga as prescrições, equivocandoas. A Clínica da Atividade, por sua vez, nos ajuda na medida em que toma o trabalho como criação e recriação permanente de formas de viver. Nesse sentido, a atividade é dirigida, histórica e processual. A Clínica da Atividade enfatiza a relevância de se construir instrumentos que viabilizem a análise dos processos de trabalho, vislumbrando a ampliação do poder de agir, o que também dialoga com o objetivo de construção de pistas para um método cartográfico em pesquisa.

É nessa direção que entendemos que as Clínicas do Trabalho são intercessoras importantes na formulação dessas pistas. O método é resultado de uma construção conjunta com aqueles que participam da pesquisa; todos são incluídos de forma lateralizada, indagando-se os especialismos. Ao privilegiarem a análise das situações concretas de trabalho, afastam-se de qualquer experimentalismo de laboratório. Perseguem não regularidades a partir de hipóteses e variáveis controladas, destacam a pesquisa dos processos em curso, priorizando-se essa dimensão temporal.

Tal atividade de pesquisa requer uma constante reformulação e análise do caminho investigativo, o que viabiliza seu próprio "desenvolvimento", não como progressão, mas como metamorfose que pode abrir uma crise nos modos habituais de trabalhar, pesquisar, enfim, de viver. A transformação tornase instrumento de produção de conhecimento e ao transformar-conhecer os vetores da atividade criam-se estratégias metodológicas para a investigação de processos e não de estados de coisas.

Dessa articulação entre Clínicas do Trabalho e o método cartográfico consideramos, então, sua dupla inscrição - a pesquisa cartográfica sempre toma como objeto a própria atividade de pesquisa e essa aposta metodológica lhe impõe problematizar-se também como atividade. A atividade aparece desdobrada como 
objeto e como método: a análise da atividade é método de investigação do objeto, não podendo deixar de ser também análise da própria atividade de pesquisa. Pesquisador e pesquisado tornam-se codependentes na análise da atividade.

O campo de pesquisa coloca problemas que forçam a pensar outros jeitos de pesquisar e no agir em situação. Não se sabe de antemão e completamente o que é ser um pesquisador. Daí, entendemos que a formação do pesquisador se efetiva em situação, partindo de um plano de imanência, plano que "[...] não precede o que vem povoá-lo, mas é constituído e remanejado na experiência" (ZOURABICHVILI, 2004, p. 76). Plano que diz, portanto, do curso da atividade do pesquisar, da experiência concreta dos pesquisadores, que se formam nesse trajeto.

É nos encontros engendrados no cotidiano, na criação de zonas de confiança, que somos forçados a pensar. Esse processo não se efetiva tão somente no plano intelectivo-racional. Como nos diz Deleuze (2000, p. 241), "[...] aquilo que só pode ser sentido sensibiliza a alma, torna-a perplexa, isto é, força-nos a colocar um problema, como se o objeto do encontro, o signo, fosse portador de problema - como se ele suscitasse problema".

Da perspectiva da atividade, pensar uma pesquisa situada, convoca-nos a habitar um plano de experimentação, plano no qual pensar, pesquisar e viver não se dissociam. Plano, insistimos, coletivo.

\section{DifERENTES “VIDAS" do TRABALHO do PESQUiSAdOR: ${ }^{1}$ UM GÊNERO PROFISSIONAL}

Desse debate derivamos algumas questões, que nos levam à proposta para formulação de um gênero pesquisador-cartógrafo. É na Clínica da Atividade que encontramos elementos para tal formulação.

Para essa abordagem nunca se está sozinho diante das provas e desafios que o real coloca. A transformação dos processos de trabalho implica sempre uma relação com outros. O sujeito, diz Clot (2010), produz um meio para viver com, ou contra, os outros, ao dirigir-se a eles ou dar-lhes as costas, é sempre com eles e em contato com o real, que o sujeito se constitui. O poder de agir é conquistado junto aos outros, uma vez que o sujeito se constrói quando começa a empregar à sua maneira as formas de condutas que os outros haviam utilizado previamente para agir (CLOT, 2010).

$\mathrm{O}$ gênero profissional ${ }^{2}$ consiste em "obrigações compartilhadas pelos que trabalham para conseguir trabalhar", mesmo considerando os obstáculos e as prescrições da organização do trabalho. Sem o recurso dessas formas comuns para agir, teríamos um desregramento da ação individual, uma queda do poder de agir e uma perda da eficácia do trabalho, entendida como essa potência criadora dos humanos.

Vejamos, então, como pensar essa dimensão genérica do trabalho de pesquisa. Uma atividade investigativa tornada mecanizada exigiria um pesquisador também mecanizado em códigos e protocolos, em ações ensaiadas, treinadas minuciosamente 
e separadas de valores e sentimentos. Esse trabalho automatizado e padronizado, sem participação efetiva do pesquisador, não existe de fato. Nenhum trabalho, por mais simples que seja, encontra no corpo do "executante" um autômato.

Metodologias de pesquisa dirigidas à prescrição e ao ajustamento pretensamente isento dos processos históricos e políticos não se abrem ao inusitado das situações concretas, ao que o campo empírico provoca e mobiliza, aos sentidos produzidos no trabalho investigativo. Qual é a função de uma atividade de pesquisa para aqueles que a exercem? Essa questão se destaca nesse debate, pois o trabalho é atividade dirigida, "[...] dirigida pelo sujeito, para o objeto e para a atividade dos outros" (CLOT, 2006, p. 78).

Dessa forma, nenhuma atividade é programada apenas em termos das necessidades ou decisões daquele que a exerce, nem mesmo em função de seus pares. Há, na atividade, uma dimensão "esfriada", "endurecida" por normas, valores sedimentados, que constituem, num certo sentido, um patrimônio coletivo.

A Clínica da Atividade (CLOT, 2010) destaca essa dimensão que atravessa os sujeitos em ato eé marcada, necessariamente, por um fazer coletivo.É impossível um fazer sem corpo, sem afetos. Nunca se trabalha só. Há necessariamente em cada ato de trabalho, um viés coletivo. A solidão, ser deixado apenas diante de si nas atividades, é vivido como da ordem do sofrimento patogênico.

Ao tomarmos a atividade de um pesquisador é possível perceber o entrelaçamento dessas dimensões: há o que se exige desse pesquisador a partir dos protocolos de controles de variáveis e utilização de determinados recursos. Por outro lado, essa dimensão é sempre preenchida de um modo singular, não há pura repetição. Um pesquisador apodera-se dessa dimensão, imprimindo-lhe uma marca. Um modo, certa cadência. Embora cada um responda a essa convocação de forma singular, essa cadência, ao mesmo tempo, alia-se à de outros pesquisadores que investigam questões semelhantes. Como ele desenvolveria aquela pesquisa? Como ele responderia a uma situação inusitada enfrentada no campo? A atividade do pesquisador é problematizada durante todo o processo de pesquisa, é colocada em análise. Atividade não é apenas objeto de pesquisa, mas sua problematização é estratégia metodológica fundamental.

Em contrapartida, não basta inventar, é necessário que a invenção seja uma estratégia compartilhada por um coletivo. Há, aqui, na relação dessas dimensões, o movimento de constituição de uma memória. É essa memória que Clot (2006) nomeia de gênero profissional. Um gênero nunca se encontra acabado, pois engloba a história de fazeres e saberes compartilhados por sujeitos em atividade dirigida em uma determinada situação.

O gênero pode ser entendido como um corpo intermediário entre os sujeitos, um interposto social situado entre eles, por um lado, e entre eles e os objetos de trabalho, por outro. De fato, um gênero sempre vincula entre si os que participam de uma situação, como coatores que conhecem, compreendem e avaliam essa situação da mesma maneira. A atividade que se realiza num gênero dado tem uma parte "explícita" e outra parte "subentendida". A parte subentendida da 
atividade é aquilo que determinados trabalhadores conhecem, esperam, apreciam ou temem; é o que lhes é comum e que os reúne em condições reais de vida; o que eles sabem que devem fazer graças a uma comunidade de avaliações pressupostas, sem que seja necessário reespecificar a tarefa cada vez que ela se apresenta. É como uma "senha" (CLOT, 2010) conhecida apenas por aqueles que pertencem ao mesmo horizonte social e profissional. Para serem eficazes, elas são econômicas e, na maioria das vezes, sequer são enunciadas. Estão marcadas no corpo dos pesquisadores, pré-organizam suas operações e seu comportamento.

Como inacabado, processual, o “[...] gênero não é um corpus ou uma tábua de leis" (CLOT, 2006, p. 47). Ele dá o tom da ação. O gênero serve de recurso para enfrentar o real. "Sem o gênero o sujeito fica só diante de si mesmo. [...] são modos de apreensão de saberes, recurso para evitar errar por si só diante da extensão das tolices possíveis" (CLOT, 2006, p. 49). Acordos tácitos.

Os modos pessoais de realizar um trabalho, que se apresentam em expressões como "o meu trabalho ou eu trabalho assim", são "[...] máscaras de um pronome pessoal ou possessivo [...]" (DELEUZE, 1997, p. 13), uma vez que o gênero está ali como potência transversal, é da ordem de uma singularização, não tem o sentido de uma generalidade. Numa atividade de pesquisa temos um conjunto de pesquisadores que se encontra na experiência de cada um. Sua ação individual está povoada por um conjunto de muitos outros, que não o deixa sozinho no campo. O estilo atualizado por cada pesquisador tanto opera uma decomposição desse gênero como a invenção de um gênero que se constitui fazendo-o variar, afirmando sua dimensão processual.

A flexibilidade de um gênero depende diretamente de ele ser realimentado por novos fazeres desenvolvidos por diferentes pesquisadores. Ao definir as fronteiras móveis do aceitável e inaceitável no trabalho de pesquisa, ao préorganizar as ações, o gênero convoca a um refazer as regras, exige um estilo, um ritmo. Uma dupla vida do estilo, fazer o que há de se fazer e ao mesmo tempo imprimir um modo singular. A problematização do trabalho do pesquisador, sua estilização, é estratégia metodológica que a Clínica da Atividade nos indica. O estilo retira ou liberta o profissional do gênero, não o negando, não contra ele, mas graças a ele, usando seus recursos, suas variantes, em outros termos, por meio de seu desenvolvimento, impelindo-o a renovar-se. O polo estilístico da atividade refere-se, portanto, aos modos singulares por meio dos quais o gênero se atualiza em situações específicas.

Essa dimensão estilística, entretanto, não é privada, não é atributo psicológico do sujeito. As criações estilísticas retrabalham o gênero, não cessam de o metamorfosear sempre que ficam "fatigados" como meio de ação (CLOT, 2010). Temos, assim, uma "poética da atividade" (AMADOR, 2009). Prioriza-se a construção de um mundo de experimentações, criando fissuras nos modos de trabalhar em pesquisa, fissuras no gênero pesquisador, dando vazão à virtualidade.

Um gênero pesquisador vai, então, forjando-se a partir de um patrimônio coletivo, de forma que não estamos sós quando entramos em campo, trata-se de uma "solidão povoada" (DELEUZE, 1997). O gênero da pesquisa cartográfica se 
forja a partir do compartilhamento de alguns princípios e diretrizes, entre os quais destacamos a atenção ao campo de forças, ao campo dos afetos de onde emergem as mudanças, o problema de pesquisa, que é plano de virtualidades, plano genealógico das formas que se oferecem ao nosso olhar. Esse plano de imanência não se refere a alguma coisa como unidade apartada de todas as coisas, muito menos a um sujeito que opera. Não depende de um sujeito. O gênero cartógrafo é feito de virtualidades, acontecimentos, singularidades.

Ao lado do contorno estável do campo com seus objetos, coexiste um plano coletivo de forças que os produzem. O gênero cartógrafo acessa esse plano, não fica restrito a metodologias de pesquisa que não apreendem essa dimensão de constituição do real, seu processo incessante de criação de novidade (ESCOSSIA, TEDESCO, 2009). Os desafios que se colocam para o gênerocartógrafo é, exatamente, pesquisar a realidade formada, mas não a dissociando dessa dimensão criadora, processual da realidade, que é esse plano coletivo de forças moventes que está sempre presente, coabita e coexiste com o das formas.

É na atenção à processualidade do mundo, fazendo intervenção, que se constitui um gênero pesquisador-cartógrafo. Acessar essa dimensão movente do real implica acessar as condições de emergência dos objetos, o que viabiliza intervir, fazer variar e atualizar outras realidades. Esse é um traço genérico essencial do gênero pesquisador cartógrafo: ampliação dos processos investigativos, não se limitando à descrição de realidades, à sua dimensão formal. Construir esse plano molecular-coletivo, ativar processos criadores de outras realidades, afirmar o caráter indissociável entre pesquisa e intervenção, construir domínios coletivos para além da constatação do que já está construído, parece-nos uma boa pista para pensar esse gênero. Perguntar o que é um gênero pesquisador-cartógrafo nos leva menos a pensar "o que", e mais, o "como" e o "quando". Tal gênero se atualiza quando há o compartilhamento de princípios e diretrizes que tomam corpo no próprio pesquisar.

\section{UM GÊNERO CARTÓGRAFO EM EXPERIMENTAÇÕES NA EDUCAÇÃO}

No ano de 2009 foi realizada uma pesquisa com docentes de uma instituição de ensino superior (IES) privada na Grande Vitória, com intuito de dar visibilidade à atividade aí desenvolvida e publicizar a complexidade das relações que a constituem (LOUZADA, BARROS, 2009). Vale ressaltar que a atividade docente se desenha entre as mutações dos cenários educacionais e dos modos de trabalhar acionados no contemporâneo. Logo, a pesquisa tomou o trabalho docente como um campo problemático, permeado por contornos indefinidos, por regras e, necessariamente, por invenções. Partiu das contribuições de autores contemporâneos dedicados à análise do trabalho, para os quais a atividade sempre exige a mobilização dos trabalhadores em um meio em constante variação. Partia-se de um princípio: por mais que se regule, por mais que haja tentativas de totalização e de ordenação da atividade docente, o trabalho necessariamente reinventa, força, escapa, resiste. 
Esse campo problemático se constituiu entrecortado de questões que não perspectivavam respostas propriamente, mas apontavam para as diretrizes convocadas para nos ajudar a pensar a pesquisa cartográfica como atividade - o construtivismo e a relação prescrito-real: como fazer análise da atividade docente? Que estratégias utilizar? Como acompanhar seus desenhos diários entre corredores, entre fazeres feitos e não feitos, ditos e não ditos, entre quadros, materiais didáticos, entre alunos, outros professores e hierarquias? Como se movimentam os docentes no cotidiano dos estabelecimentos de ensino privado? Como se gerem entre formas panópticas (FOUCAULT, 1998), corporificadas pelas câmeras, pela vigilância dos alunos, dos chefes dos corredores, das coordenações pedagógicas e insidiosamente pela autovigilância, que tem marcado o trabalho nas instituições privadas de ensino superior? Como articulam saberes e fazeres minuciosamente agenciados pelas tecnologias de poder (FOUCAULT, 1995) que os fazem seguir as regras dos estabelecimentos de ensino privado? Como lidam com seus fazeres transformados em números, feito posição em uma escala? Como tecem outros usos não previstos? Como agenciam produções de sentidos em suas atividades? Buscavam-se os processos microgestionários do trabalho docente.

Assim, o trabalho docente foi tomado como estranhamento, como algo que ultrapassa as didáticas, os treinamentos, as reuniões pedagógicas, os planos de ensino, os cronogramas de aula, os recursos didáticos e ousou-se acompanhar as mutações das paisagens e delinear outros modos de trabalhar como professor. Ao trabalhar, os docentes fabricam uma cadência, a invenção de um "passo", de um modo de se deixar levar pelos traçados, escapando das formas, dos compassos, dos lugares marcados.

A pesquisa utilizou os princípios da cartografia, de acompanhar os movimentos, de colocar-se junto àqueles que trabalham, articulados com as ferramentas metodológicas da Clínica da Atividade. Foram construídas algumas estratégias metodológicas: entrevistas (Técnica de Instrução ao Sósia); filmagem de uma aula; autoconfrontação; uma roda de conversa com alunos; observação do cotidiano do estabelecimento. Durante todo o processo um grupo associado de professores construía com a pesquisadora cada passo da pesquisa. Importante salientar que essas estratégias foram configuradas e reconfiguradas durante todo o processo de pesquisar, na intercessão da pesquisa com o campo.

A técnica de Instrução ao Sósia, proposta por Oddone et al. (1986), é um método de intervenção junto aos trabalhadores, que pretende fortalecer um coletivo de trabalho, mais do que simplesmente um acesso aos dados. Se eu fosse substituir você amanhã, como eu deveria me portar para não ser reconhecido? Essa era a questão disparadora das entrevistas. Nas primeiras, a análise da atividade se realizou timidamente. Para Clot (2007), a palavra não é para escutar o vivido, ela é feita para agir, é um diálogo profissional para transformar a situação. As conversas, entremeadas pela instrução ao sósia, propiciaram estranhamentos mútuos em relação à atividade de trabalho e desdobraram-se em muitas outras breves e intensas conversas. 
Os docentes que participaram do processo investigativo trabalham, também, em outras IES privadas da Grande Vitória, nos quais são horistas que ministram de dez a 40 horas-aulas semanais. Possuem de dois meses a 13 anos de experiência em sala de aula no ensino superior. Trabalham de dois meses a 12 anos no atual local de trabalho onde a pesquisa foi realizada, sendo que três docentes trabalham em duas ou mais instituições de ensino e cinco possuem outra atividade profissional além do exercício da docência. Quase todos já estiveram trabalhando em outras instituições privadas. Possuem formações variadas, como História, Matemática, Psicologia, Enfermagem, Nutrição, Filosofia, Educação Física e Farmácia. Nas conversas os sujeitos eram instigados a pensar como efetivamente trabalham, como executam suas atividades.

Outra estratégia metodológica utilizada foi a constituição de um grupo associado, isto é, um grupo de professores de diferentes disciplinas do curso de Psicologia, que referenciava, reconduzia, ressignificava a própria atividade da pesquisa. Esse grupo, nômade por excelência, não foi realizado em um dia ou lugar determinado, mas acontecia sempre que era necessário repensar os passos seguintes da pesquisa, em salas da própria instituição reservadas com antecedência para esse fim. Esse retorno das conversas aos docentes-parceiros, essa aliança/grupalidade, produziu desvios na condução da pesquisa: decidiam que cenas filmar, quais questões deveriam ser colocadas nas entrevistas, a composição espacial das negociações sobre o como filmar, o que filmar, quando filmar, enfim, para, posteriormente, tomar a atividade de trabalho como objeto de análise coletiva. Assim, a proposta de filmagem de uma aula, advinda dessas conversas, efetivou-se. Uma professora, que não compunha o grupo associado, foi convidada e aceitou prontamente, uma vez que, segundo seu depoimento, acreditava que a pesquisa poderia contribuir para que a situação insustentável vivida no estabelecimento pudesse ser transformada.

E a pesquisa foi-se delineando, entre conversas e análises, com as imagens ajudando a recolocar problemas para a atividade docente. Um exercício constante de atualização de modos de trabalhar em uma instituição privada e ao mesmo tempo na atualização dos princípios cartográficos da pesquisa.

Disparado pela filmagem da atividade docente, realizou-se uma autoconfrontação $^{3}$ (CLOT, 2006, 2010), momento em que uma professora traz para o diálogo com o pesquisador a atenção sobre suas ações, como decide ou organiza a condução de sua atividade. Nessa metodologia a professora, diante das imagens da sua aula que foram filmadas, explicava para a pesquisadora como fazia seu trabalho, nos seus menores detalhes: como e para quê fazia, as estratégias criadas para dar conta da tarefa de ministrar uma aula de Psicologia numa universidade particular. Ao ser confrontada por sua atividade, ao se ver trabalhando, a professora analisava as decisões, os movimentos, os pontos altos da aula, suas tensões e seus momentos de descontrações.

Nesse diálogo havia a produção de uma cadência, que se compunha por uma mistura entre alunos e professores em torno de uma ideia a ser trabalhada - desdobramentos da atividade real. Estava sendo composta certa visibilidade 
para a experiência de trabalho docente, possibilitando a análise coletiva das arbitragens, que expressam o real da atividade. A aula é apenas parte do trabalho, afirmava a docente. $\mathrm{O}$ real da atividade atravessa a aula: a escolha de um autor, e não de outro; a escolha de um texto e não de outro; o momento em que se escolhe trabalhar esse texto, depois do que, antes do que; a escolha de certo roteiro e não de outros; inúmeras microdecisões povoam uma aula.

Quando interrogada sobre seu fazer, a professora trouxe uma série de exigências feitas a si na condução da atividade: é preciso esforço para aprender o nome dos alunos, o que exige de si um andar em sala, falar alto. Salienta que tudo isso é necessário para manter a atenção dos alunos. Exercer a atividade docente presentifica os professores incorporados na aluna que a professora foi: ela não gostava dos professores de tons baixos e monótonos, dos professores tornados estátuas, por isso ela se esforçava para dinamizar a aula por meio de estratégias que se forjavam a cada momento, a depender do que a situação convocava. Esse modo singular de trabalho atravessa o gênero, rebate-se nele, traz também as experiências de seus professores. Compõem um gênero profissional, pois os outros professores do grupo associado se reconheciam naquela atividade, mas também se diferenciavam nela, pois a aula da professora não é apenas dela, é atravessada pelo gênero. É composição de estilos, é inacabada e processual, assim como o trabalho do pesquisador.

A pesquisa convoca a professora a se confrontar com ela mesma, contudo, nessa confrontação se criam condições de visibilidade daquilo que está para além dela: o gênero que ela atualiza e reinventa (estiliza). Por outro lado, a pesquisa também se confronta consigo quando acompanha os movimentos do trabalho dos professores. A atividade de pesquisa, nessa direção, também precisa se dar conta de como singulariza esse gênero profissional, atualizando-o. Os encontros com o grupo associado de professores iam definindo cada passo da pesquisa, que se modulavam também a partir de um patrimônio coletivo compartilhado e sustentado por pesquisadores nas experiências singulares. As questões referentes aos estilos de ensino eram pautadas nos debates e os tensionamentos experimentados não levaram, em nenhum momento, à desqualificação das diferentes práticas atualizadas, mas serviam de material para o fortalecimento desse gênero profissional.

O gênero é obra aberta, que se constitui processualmente, arrasta uma memória da qual e na qual a professora inventa uma paisagem. E é importante que a maneira como a professora trabalha possa se atualizar nos modos de trabalhar dos professores das salas ao lado, para que seu exercício não se torne solitário. A professora e o pesquisador atualizam gêneros.

A atividade docente se modulava ao longo da autoconfrontação, como uma atividade dirigida a si (suas exigências e necessidades) e dirigidas aos outros, em uma procura sensível pela expressão do outro, pelo aluno que desejava falar, pelo aluno que falava raramente e então era preciso ouvi-lo atento, pelos alunos que se perderam na aula. Considera que essas modulações, tecidas entre si e os outros, e por meio delas, reorienta o rumo da aula. "Uma boa aula", diz a professora no início da autoconfrontação. "Essa foi uma boa aula. Foi um cansaço bom!". 
Nessa aula, na aula da sala ao lado, nas aulas das salas das faculdades próximas, ao exercer a atividade, corporificam-se modos singulares de ser professor, que não se reduzem às práticas de dominação, nas quais "[...] as relações de poder, em vez de serem móveis e permitirem aos diferentes parceiros uma estratégia que os modifique, se encontram bloqueadas e cristalizadas" (FOUCAULT, 2004, p. 266).

Longe de se restringir a uma descrição da aula, limitada aos contornos formais do que habitava o espaço de trabalho da professora, o empenho foi conhecer-acessar um movimento que a constituía, constituía os pesquisadores, os professores, os alunos, a sala de aula, a instituição privada de ensino e a própria pesquisa.

Dessa investigação desdobrou-se tanto o realce aos modos singulares e coletivos da atividade: cooptações e rupturas; gestão piramidal do trabalho; cumprimento de regras e produção de normas - e, também a criação de uma rede de amizade, de um coletivo fortalecido, para a análise das atividades docentes em meio às prescrições. Isso foi evidenciado em diferentes momentos da pesquisa.

O grupo associado, nômade por característica, marcava insistentemente, "olha aí, isso precisa entrar na pesquisa"; "não deixa isso passar"; "anota aí: agora eu sei que eu sempre começo a aula desse jeito". Com olhares que buscavam o pesquisador durante uma reunião de planejamento, já diziam da importância do registro e da análise do que estava sendo dito. O grupo compunha uma potência analítica para pesquisa quando o pesquisador encontrava-se demasiadamente entorpecido.

Uma grande marca dessa pesquisa foi percepção de que embora a atividade docente fosse o objeto da pesquisa, insistentemente houve a problematização da atividade do pesquisador como uma estratégia metodológica. Atividade do professor e atividade do pesquisador foram colocadas em análise durante todo o percurso investigativo. Uma trabalhadora docente a lecionar, um pesquisador a pesquisar, ambos em atividade, processos de invenção e criação os atravessam: existir em meio às imprevisibilidades, contornar obstáculos, forjar para além das individualidades de docente e pesquisador.

Assim, a metodologia utilizada na pesquisa incluía uma análise da atividade de pesquisa, afirmando-se a dupla inscrição própria do gênero cartógrafo, que toma a atividade como objeto de pesquisa e, ao mesmo tempo, indaga o modo como sua atividade se faz no processo e, para isso, constituiram-se dois personagens umpesquisador-de-jaleco-em-mim e um aprendiz-de-cartógrafo-em-mim (LOUZADA; BARROS, 2009), que durante a pesquisa se embatem, combatem, misturam, produzindo desvios nos modos de pesquisar. A análise da atividade docente incluiu, portanto, a análise da atividade do pesquisador que se fazia por meio de variados estilos de conversas com personagens que participaram da investigação. 
A pesquisa se modulou mais uma vez quando da sua escrita. Ela disparou um modo de escrever uma tese, que se diferenciou de uma análise tradicional de dados, conforme habitualmente era feita no programa de pós, onde a pesquisa foi realizada. As falas e os silêncios das conversas ganharam o tom de crônicas, que trazem a atividade docente, seus passos, suas trilhas.

\section{CONSIDERAÇões FINAIS}

O gênero-cartógrafo, os atos de cada pesquisador, são atos de conhecer, que acessam um plano de forças, habitando-o, transformando-o e intervindo. A pesquisa cartográfica como gênero comporta um conjunto de princípios e diretrizes que o caracteriza e carrega, por sua vez, um patrimônio coletivo.

Esse gênero seria um conjunto de ações mobilizadas por um problema situado, convocadas por ele. Ele seria, ao mesmo tempo, sedimentação e prolongamento do que já foi feito pelos pesquisadores, um patrimônio coletivo, incluindo também o que não foi feito, o que foi pensado, o que deixou de ser feito e os impasses experimentados. Seria um precedente para a atividade de pesquisa em curso: o que outrora foi feito pelos coletivos de pesquisa, nas parcerias engendradas, nas situações concretas partilhadas.

Destaca-se, nessa linhagem de análise, o fato de que toda atividade é tomada como atravessamentos múltiplos que se agenciam, se interconectam, demandando escolhas e decisões. O poder de agir se constitui num trânsito, no qual o coletivo devém singular e o singular devém coletivo, num movimento no qual singular e coletivo, estilo e gênero, não são dicotômicos, mas efeito de conexão.

Diríamos, então, que o pesquisador cartógrafo produz um gênero que conforma um campo linguístico e extralinguístico que não tem a ver com uma redução do vivido a um corpus de protocolos e regulamentos metodológicos; diz respeito a uma incessante invenção coletiva de um plano de referência, certa disposição de elementos diversos capazes de produzir sentido, colocando em funcionamento modos de pesquisar. Tal produção se elabora no âmbito de um coletivo sendo, portanto, um meio de constituir um coletivo de pesquisadores como fonte de sua renovação e movimento. Gênero pesquisador-cartógrafo que se define como experiência coletiva. Sendo um gênero, o pesquisador está sempre submetido à prova do real, pois não há apenas "obrigações" metodológicas a serem respeitadas, mas, também, recurso a renovar e método a ajustar. O pesquisador age por meio de gêneros na realização das exigências da ação.

Portanto, estar em campo ao pesquisar não implica solidão, portanto. A atividade de pesquisa tem memória. Nunca entramos no campo sozinho. A expertise do pesquisador é forjada nesse ponto de conexão entre uma história singular e a história de todos. A atividade de pesquisa ou a pesquisa do ponto de vista da atividade seria, então, usina permanente de um movimento de "estilização dos gêneros e variação de si". É isso que permite que o dado seja eventualmente criado. 
Afirmar o gênero pesquisador-cartógrafo é trazer para o diálogo a constituição de um ethos de pesquisa em que se destaca uma dupla inscrição, ou seja, um gênero que sempre toma como objeto uma atividade e tem como aposta metodológica a problematização da atividade do pesquisador. Um gênero que convoca para o diálogo pesquisadores engajados num modo de fazer pesquisa que considera a experiência situada com suas irregularidades e imprevistos. Neste texto indicamos algumas questões e pistas para pensar um gênero cartógrafo. Não caberia nesse quadro delineado uma direção formativa tomada como um percurso a ser feito, definido a priori, e que conduziria o pesquisador a um determinado lugar predefinido, a um perfil considerado o ideal para um cartógrafo. Não se trata de formar um pesquisador para aplicar de forma automática procedimentos metodológicos, já que entre o prescrito para a realização de uma pesquisa e o real há um vazio de normas a ser trabalhado. Tornar-se cartógrafo é sempre um exercício local e parcial e se efetiva por meio de práticas, é um processo incessante de renormatização e de criação de um meio, talhado no caminho que se vai instituindo no processo investigativo. Nessa pista do método cartográfico consideramos que a atividade do cartógrafo é também constituição de um gênero e via de estilização, pois estamos sempre no meio de certo aprendizado, numa certa transformação, em meio a intervenções recíprocas. É em atividade de pesquisa que se forma um pesquisador-cartógrafo.

É em atividade de pesquisa que se forja um gênero pesquisador.

\section{Notas}

${ }^{1}$ Clot (2010, p. 290) afirma que um “[...] ofício tem várias vidas, o que torna possível seu desenvolvimento". No seu entendimento um ofício é ao mesmo tempo pessoal, impessoal, interpessoal e transpessoal e é nessa direção que estamos considerando o trabalho em pesquisa um ofício constituído por várias instâncias.

${ }^{2}$ Nessa linha de argumentação, Clot (2010) formula o conceito de gênero profissional, fazendo-o derivar do conceito de gênero discursivo de Bakhtin (2000), que é um terceiro termo entre o prescrito e o real.

${ }^{3}$ Autoconfrontação cruzada é um método propostos por Clot e colaboradores, que busca produzir um deslocamento do trabalhador do lugar de quem cumpre tarefas, com um grau maior ou menor de automatismo, para o lugar de quem analisa os processos trabalho. O trabalhador, ou o saber da experiência por ele operado, se torna primeiro na análise da atividade. O que se propõe com o método da autoconfrontação cruzada é uma forma de co-análise do trabalho, praticada no ambiente habitual.

\section{REFERÊNCIAS}

AMADOR, F. Entre prisões da imagem, imagens da prisão: um dispositivo tecnopoético para uma clínica do trabalho. 2009. Tese (Doutorado em Informática na Educação)-Programa de Pós-Graduação em Informática na Educação, Universidade Federal do Rio Grande do Sul, Porto Alegre, 2009.

ATHAYDE, M.; BRITTO, J. Ergologia e clínica do trabalho. In: BENDASSOLLI, P.; SOBOLL, L. A. (Org.). Clínicas do trabalho. São Paulo: Atlas, 2010. p. 258281. 
BAKHTIN, M. A estética da criação verbal. São Paulo: Martins Fontes, 2000.

CANGUILHEM, G. O normal e o patológico. 5. ed. Rio de Janeiro: Forense Universitária, 2000.

CLOT, Y. A função psicológica do trabalho. Petrópolis, RJ: Vozes, 2006.

CLOT, Y. A psicologia do trabalho na França e a perspectiva da clínica da atividade. Palestra proferida na Universidade Federal Fluminense, no Instituto de Ciências Humanas e Filosofia, 18 set. 2007.

CLOT, Y. Clínica da atividade e poder de agir. Belo Horizonte: Fabrefactum, 2010 .

DELEUZE, G. Crítica e clínica. São Paulo: Editora 34, 1997.

DELEUZE, G. Conversações. São Paulo: Editora 34, 2000.

DELEUZE, G.; GUATTARI, F. O que é filosofia? Rio de Janeiro: Editora 34, 1997.

ESCÓSSIA, L. TEDESCO, S. O coletivo de forças como plano de experiência cartográfica. In: PASSOS, E.; KASTRUP, V. ESCÓSSIA, L. (Org.). Pistas do método da cartografia: pesquisa-intervenção e produção de subjetividade. Porto Alegre: Sulina. 2009. p. 109-130.

FOUCAULT, M. Sobre a genealogia da ética: uma revisão do trabalho. In: DREYFUS, H.; RABINOW, P. (Ed.). Michel Foucault, uma trajetória filosófica: para além do estruturalismo e da hermenêutica. Rio de janeiro, Forense Universitária, 1995. p. 253-278.

FOUCAULT. M. Nietzsche, a genealogia e a história. In: . Microfísica do poder. Rio de Janeiro, Graal, 1998. p.15-37.

FOUCAULT, M. A ordem do discurso. São Paulo: Loyola, 2004.

LHUILIER, D. Cliniques du travail. Toulouse: Érès, 2006.

LOUZADA, A. P.; BARROS, M. Afirmando a potência de cirandar: cartografia dos processos de produção de saúde na docência. In: RESENDE, S.; BARROS, M. E. B.; FERIGATO, S. (Org.). Conexões: saúde coletiva e políticas de subjetividade. São Paulo: Aderaldo \& Rothschild, 2009. p. 394-412.

ODDONE, I. et al. Ambiente de trabalho: a luta dos trabalhadores pela saúde. São Paulo: Hucitec, 1986. 
PASSOS, E.; BENEVIDES DE BARROS, R. A cartografia como método de pesquisa-intervenção. In: PASSOS, E.; KASTRUP, V. ESCÓSSIA, L. (Org.). Pistas do método da cartografia: pesquisa-intervenção e produção de subjetividade. Porto Alegre: Sulina. 2009. p. 17-31.

SCHWARTZ, Y. Travail et philosophie. Toulouse: Octarès. 1992.

SCHWARTZ, Y. Os ingredientes da competência: um exercício necessário para uma questão insolúvel. Educação \& Sociedade, Campinas, ano XIX, n. 65, p. 101-139, 1998.

SCHWARTZ, Y. Le paradigme ergologique ou un métier de philosophe. Toulouse: Octarés, 2000.

WISNER, A. A inteligência no trabalho. São Paulo: Fundacentro, 1999.

ZOURABICHVILI, F. O vocabulário de Deleuze. Rio de Janeiro: RelumeDumará, 2004.

Recebido em: 05 de maio de 2013 Aceito em: 24 de agosto de 2013 
